\title{
1,25-Dihydroxyvitamin D modulates L-type voltage-gated calcium channels in a subset of neurons in the developing mouse prefrontal cortex
}

\author{
Helen Gooch (1)', Xiaoying Cui ${ }^{1}$, Victor Anggono (1) ${ }^{1,2}$, Maciej Trzaskowski ${ }^{3}$, Men Chee Tan ${ }^{1,2}$, Darryl W. Eyles ${ }^{1,4}$,

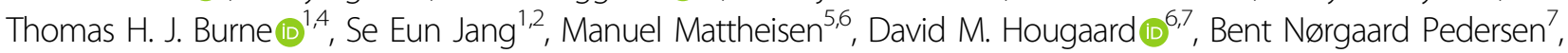 \\ Arieh Cohen ${ }^{7}$, Preben B. Mortensen ${ }^{6,8,9}$, Pankaj Sah ${ }^{1,10}$ and John J. McGrath $\mathbb{B}^{1,4,8}$
}

\begin{abstract}
Schizophrenia has been associated with a range of genetic and environmental risk factors. Here we explored a link between two risk factors that converge on a shared neurobiological pathway. Recent genome-wide association studies (GWAS) have identified risk variants in genes that code for L-type voltage-gated calcium channels (L-VGCCS), while epidemiological studies have found an increased risk of schizophrenia in those with neonatal vitamin $D$ deficiency. The active form of vitamin $\mathrm{D}\left(1,25(\mathrm{OH})_{2} \mathrm{D}\right)$ is a secosteroid that rapidly modulates L-VGCCs via non-genomic mechanisms in a range of peripheral tissues, though its non-genomic effects within the brain remain largely unexplored. Here we used calcium imaging, electrophysiology and molecular biology to determine whether 1,25 $(\mathrm{OH})_{2} \mathrm{D}$ non-genomically modulated L-VGCCs in the developing prefrontal cortex, a region widely implicated in schizophrenia pathophysiology. Wide-field $\mathrm{Ca}^{2+}$ imaging revealed that physiological concentrations of $1,25(\mathrm{OH})_{2} \mathrm{D}$ rapidly enhanced activity-dependent somatic $\mathrm{Ca}^{2+}$ levels in a small subset of neurons in the developing PFC, termed vitamin D-responsive neurons (VDRNs). Somatic nucleated patch recordings revealed a rapid, $1,25(\mathrm{OH})_{2} \mathrm{D}$-evoked increase in high-voltage-activated (HVA) $\mathrm{Ca}^{2+}$ currents. Enhanced activity-dependent $\mathrm{Ca}^{2+}$ levels were mediated by L-VGCC but not associated with any changes to Cacnalc (L-VGCC pore-forming subunit) mRNA expression. Since L-VGCC activity is critical to healthy neurodevelopment, these data suggest that suboptimal concentrations of 1,25 $(\mathrm{OH})_{2} \mathrm{D}$ could alter brain maturation through modulation of L-VGCC signalling and as such may provide a parsimonious link between epidemiologic and genetic risk factors for schizophrenia.
\end{abstract}

\section{Introduction}

Schizophrenia is a poorly understood group of mental disorders with a lifetime prevalence of $0.7 \%^{1}$. The disorder is associated with both common and rare genetic variants, as well as a range of environmental exposures. Recent genome-wide association studies have identified genetic variants of L-type voltage-gated calcium channel (L-

\footnotetext{
Correspondence: John J. McGrath (j.mcgrath@uq.edu.au)

'Queensland Brain Institute, University of Queensland, St. Lucia, QLD 4072,

Australia

${ }^{2}$ Clem Jones Centre for Ageing Dementia Research, University of Queensland,

St. Lucia, QLD 4072, Australia

Full list of author information is available at the end of the article.

These authors contributed equally: Helen Gooch, Xiaoying Cui
}

VGCC) subunits that are associated with an increased risk for schizophrenia (CACNA1C, CACNB2, CACNA2D1) ${ }^{2}$. Evidence from whole-exome sequencing ${ }^{3}$ and copy number variant studies ${ }^{4}$ have also implicated L-VGCCrelated genes as risk factors for schizophrenia. While these risk variants do not result in gross dysfunction in LVGCCs, it is thought that they may contribute to subtle changes in the developmental expression or activity of LVGCC subunits ${ }^{5}$, potentially leading to neurodevelopmental abnormalities. Indeed, modulation of L-VGCC activity during brain development has been shown to alter the extent and complexity of dendritic arborisation, as well as the developmental maturation and migration of

\section{(c) The Author(s) 2019}

(c) (i) Open Access This article is licensed under a Creative Commons Attribution 4.0 International License, which permits use, sharing, adaptation, distribution and reproduction cc) in any medium or format, as long as you give appropriate credit to the original author(s) and the source, provide a link to the Creative Commons license, and indicate if changes were made. The images or other third party material in this article are included in the article's Creative Commons license, unless indicated otherwise in a credit line to the material. If material is not included in the article's Creative Commons license and your intended use is not permitted by statutory regulation or exceeds the permitted use, you will need to obtain permission directly from the copyright holder. To view a copy of this license, visit http://creativecommons.org/licenses/by/4.0/. 
neurons in both the hippocampus ${ }^{6,7}$ and cortex ${ }^{8}$. Moreover, deletion of Cacna1c during embryonic development, but not in adulthood, resulted in altered adult behavioural phenotypes relevant to schizophrenia ${ }^{9}$. Taken together, these findings support the hypothesis that factors that alter L-VGCC activity in the developing brain may contribute to risk of schizophrenia.

There is also a growing body of epidemiological evidence implicating developmental vitamin D deficiency as a risk factor for schizophrenia. Epidemiological studies have demonstrated that winter/spring season of birth is associated with increased risk for schizophrenia-vitamin $\mathrm{D}$ deficiency is most prevalent during these seasons ${ }^{10}$. There is also an increased risk of schizophrenia in darkskinned migrants to Nordic and northern European countries, groups known to be at increased risk of vitamin D deficiency ${ }^{11,12}$. Neonatal vitamin D status has also been directly linked to an increased risk for schizophrenia. A case-control study $(n=848)$ found that neonates with vitamin $\mathrm{D}$ deficiency had a twofold increased risk of being diagnosed with schizophrenia in later life (Incidence Rate Ratio $=2.1 ; 95 \%$ confidence intervals (CIs) $1.3-3.5)^{13}$. This finding was recently replicated using a larger sample $(n=2602 ; \quad$ Incidence Rate Ratio $=1.44 ; 95 \%$ CIs $1.12-1.85)^{14}$. The biological plausibility of vitamin D deficiency as a risk factor for schizophrenia is supported by the expression of the vitamin D receptor (VDR) and 25-hydroxyvitamin D-1 $\alpha$-hydroxylase (an enzyme required for 1,25-dihydroxyvitamin $\mathrm{D}\left(1,25(\mathrm{OH})_{2} \mathrm{D}\right)$ production) in the human brain ${ }^{15}$. Further, rodent experiments have demonstrated that transient developmental vitamin $\mathrm{D}$ deficiency is associated with persistent neurochemical and behavioural changes that involve biological pathways of interest to schizophrenia, including the dopamine system ${ }^{16,17}$.

To date, this research has been based on the assumption that the biological consequences of developmental vitamin D deficiency operated via the classical genomic pathways. For example, vitamin D deficiency impacts on neuronal proliferation and differentiation through transcriptional activity, which is mediated by VDR forming a heterodimer with the retinoic acid $\mathrm{X}$ receptor and then binding to response elements in the genome ${ }^{18-22}$. Longterm $1,25(\mathrm{OH})_{2} \mathrm{D}$ treatment has also been shown to confer neuroprotective effects following insult, which correlated with the downregulation of both L-VGCC mRNA expression and L-VGCC surface expression ${ }^{23,24}$. However, despite the documented non-genomic effects of $1,25(\mathrm{OH})_{2} \mathrm{D}$ on L-VGCC-dependent calcium influx in several tissues including bone ${ }^{25}$, muscle ${ }^{26}$ and pan$\operatorname{creas}^{27,28}$, its non-genomic effects within the brain remain largely unexplored. To our knowledge, only a single study has implicated $1,25(\mathrm{OH})_{2} \mathrm{D}$ with rapid changes to $\mathrm{Ca}^{2+}$ signalling in the brain, using liquid scintillation spectrometry to reveal $1,25(\mathrm{OH})_{2} \mathrm{D}$-induced slice uptake of ${ }^{45} \mathrm{Ca}^{2+}$ that was dependent on L-type, but not N-type, VGCC activity ${ }^{29}$. Based on the convergence of these genetic and environmental risk factors for schizophrenia upon L-VGCC-related mechanisms, we investigated the non-genomic effects of $1,25(\mathrm{OH})_{2} \mathrm{D}$ on neuronal L-VGCC activity in the developing brain using both functional and molecular approaches.

\section{Material and methods}

All experimental and animal care procedures were in accordance with the Australian Code of Practice for the Care and Use of Animals for Scientific Purposes and approved by the University of Queensland Animal Ethics Committee.

\section{Slice preparation}

Balb/c mice (P8-P12) of both sexes were deeply anaesthetised using isoflurane anaesthesia, decapitated, and the brain rapidly removed and submerged in ice-cold oxygenated artificial cerebrospinal fluid (ACSF) containing (in $\mathrm{mM}$ ): $87 \mathrm{NaCl}, 2.5 \mathrm{KCl}, 25 \mathrm{NaHCO}_{3}, 25$ glucose, 50 sucrose, $4 \mathrm{MgCl}_{2}, 0.5 \mathrm{CaCl}_{2}$, and $1.2 \mathrm{NaH}_{2} \mathrm{PO}_{4}, \mathrm{pH} 7.4$ $\left(95 \% \mathrm{O}_{2}\right.$ and $\left.5 \% \mathrm{CO}_{2}\right)$. Coronal slices $(300 \mu \mathrm{m})$ containing prefrontal cortex (PFC) were prepared for both nucleated patch recordings and $\mathrm{Ca}^{2+}$ imaging protocols using a Vibratome (VT1000S, Leica) and incubated at $34^{\circ} \mathrm{C}$ for $30 \mathrm{~min}$ in ACSF, containing (in $\mathrm{mM}$ ): $118 \mathrm{NaCl}, 2.5 \mathrm{KCl}$, $25 \mathrm{NaHCO}_{3}, 10$ glucose, $1.3 \mathrm{MgCl}_{2}, 2.5 \mathrm{CaCl}_{2}$, and 1.2 $\mathrm{NaH}_{2} \mathrm{PO}_{4}$, pH 7.4 $\left(95 \% \mathrm{O}_{2}\right.$ and $\left.5 \% \mathrm{CO}_{2}\right)$. PFC neurons were visualised using an upright microscope (Olympus BX50WI, Japan) and infrared differential interference contrast optics at high magnification.

\section{Calcium imaging}

Following 25-min recovery at $34{ }^{\circ} \mathrm{C}$, slices were loaded with Texas Red Hydrazide (TxRed; $1.8 \mu \mathrm{M}$; ThermoFisher Scientific; Ex/Em 582/602) for 5 min, before being transferred into standard ACSF and equilibrated to room temperature for at least $30 \mathrm{~min}$. Slices were then transferred to a small volume $(3 \mathrm{~mL})$ incubation chamber made in-house for Cal-520 AM loading (AAT Bioquest; Ex/Em $492 / 514$ ) at either room temperature or $34^{\circ} \mathrm{C}$ (PhysioSuite, Kent Scientific) for 2-3 h, containing (in $\mathrm{mM}$ ): 118 $\mathrm{NaCl}, 2.5 \mathrm{KCl}, 25 \mathrm{NaHCO}_{3}, 10$ glucose, $1.3 \mathrm{MgCl}_{2}, 2.5$ $\mathrm{CaCl}_{2}$, and $1.2 \mathrm{NaH}_{2} \mathrm{PO}_{4}, 0.01 \mathrm{Cal}-520,0.03 \%$ pluronic F127, $\mathrm{pH} 7.4\left(95 \% \mathrm{O}_{2}\right.$ and $\left.5 \% \mathrm{CO}_{2}\right)$. Slices were incubated in L-VGCC blocker nifedipine (nif; $10 \mu \mathrm{M}$ ) for $>30 \mathrm{~min}$ prior to imaging where indicated and were imaged in alternation with bath application of $1,25(\mathrm{OH})_{2} \mathrm{D}$ alone. Following loading, slices were transferred to a submerged imaging chamber perfused with oxygenated ACSF maintained at $25 \pm 1{ }^{\circ} \mathrm{C}$ (TC-324B, Warner) and secured with a platinum harp strung with parallel nylon threads. Cell 
depolarisation was evoked using electric field stimulation (efs) generated by two parallel platinum electrodes, separated by a distance of $5 \mathrm{~mm}$, with an isolated stimulator (DS2A, Digitimer Ltd; square pulse, $1 \mathrm{~ms}, 0.05 \mathrm{~Hz}$, $20-40 \mathrm{~V})$. Both the imaging and stimulation systems were controlled by Metafluor (version 7.10, Molecular Devices) through a 74HC08 AND gate box (Scitech). Fluorescence imaging of the developing PFC was performed using a Polychrome V monochromator (TILL Photonics) combined with an sCMOS camera (pco.edge 5.5, PCO) and $\times 40$ water-immersion objective, which captured a visual field of approximately $411 \mu \mathrm{m} \times 338 \mu \mathrm{m}$. Wide-field Cal$520(50 \mathrm{~ms})$ and TxRed $(30 \mathrm{~ms})$ fluorescent images were acquired at $0.1 \mathrm{~Hz}(2 \times 2$ binning), with every second of Cal-520 exposure time-locked to efs $(0.05 \mathrm{~Hz})$. Cal-520 and TxRed fluorescent images were collected using a multi-band dichroic and filter set (FITC/TxRed-A, Semrock; Supplementary Fig. 1a-c). TxRed images were collected to monitor for changes in $z$-depth via in-plane astrocytic processes $(<3 \mu \mathrm{m})$, and manual depth corrections were made as required. Imaging sessions were excluded from the data set when changes in $z$-depth were observed (movement of the imaged $z$-plane towards or away from the objective lens). Instantaneous $\Delta F / F$ $(0.05 \mathrm{~Hz})$ was calculated for individual somatic regions of interest (ROIs) as fluorescence during field stimulation (F2) minus the immediately preceding fluorescence at rest (unstimulated, F1), divided by the fluorescence at rest (F1, Fig. 1a). Single-cell ROI fluorescence levels were extracted offline from these acquired temporal $z$-stacks using Fiji. Background subtraction (rolling ball, radius 50 pixels) and $X Y$ image stabilisation were applied using built-in plugins. Instantaneous $\triangle F / F$ analysis of wide-field images was automated using custom MATLAB scripts and converted to txt files that were baselined (flat or extrapolated sloping function) and quantified using the Axograph software (Axograph $\mathrm{X}$, version 1.7.2). ROI data met signal-to-noise inclusion criteria if bath application of $1,25(\mathrm{OH})_{2} \mathrm{D}$ induced a percentage change in the instantaneous $\Delta F / F$ that exceeded three standard deviations of $>5 \mathrm{~min}$ pre$1,25(\mathrm{OH})_{2} \mathrm{D}$ baseline $\Delta F / F$ amplitude. $1,25(\mathrm{OH})_{2} \mathrm{D}$ was bath applied at the physiological concentration of $0.1 \mathrm{nM}^{30}$ from a 1-mM stock solution (dimethyl sulfoxide (DMSO)). Where specified, imaging sessions were conducted in the presence of synaptic blockers (synblock), which included 6-cyano-7-nitroquinoxaline-2-3-dione (10 $\mu \mathrm{M}$; Tocris), D-2-amino-5-phosphonopentanoic acid (50 $\mu \mathrm{M}$; Tocris) and picrotoxin (100 $\mu \mathrm{M}$; Sigma-Aldrich); the L-VGCC agonist Bay K8644 (BAYK; $2.5 \mu \mathrm{M}$; SigmaAldrich); or the L-VGCC antagonist nif $(10 \mu \mathrm{M}$; SigmaAldrich). The duration of an imaging session baseline was dependent on the applied pharmacology: ACSF 10-20 min, synblock 20 min, nif 20 min $^{31,32}$ (Supplementary Fig. 1d). Neurons that ceased to respond to electrical stimulation following bath application of synblock were excluded from the total cell count imaged per slice. Only electrically responsive, TxRed-negative cells were included in vitamin D-responsive neuron (VDRN) subsets. VDRN slice Responding \% was calculated from the total number of Cal-520-positive cells in focus per imaged area (TxRed-positive and TxRed-negative) to avoid errors stemming from inaccurate TxRed staining. As such, VDRN Proportion Responsive (\%) statistics may underestimate the percentage of imaged neurons that were VDRNs.

\section{Nucleated patch recordings}

High-voltage-activated (HVA) $\mathrm{Ca}^{2+}$ channel currents were recorded in nucleated patch configuration ${ }^{33}$ using barium as the charge carrier. Nucleated patches were extracted from the soma of visually identified L2/3 PFC neurons (series resistance $<15 \mathrm{M} \Omega$ ). Briefly, negative pressure (10-15 kPa; Series 475 MARK III Digital Manometer, Dwyer Instruments, IN, USA) ${ }^{34}$ was applied to the patch pipette in whole-cell configuration, drawing the nucleus towards the pipette tip as it was slowly withdrawn from the soma, to produce an outside-out patch of somatic membrane internally scaffolded by the nucleus. Following isolation of the nucleated patch, negative pipette pressure was reduced to $3-5 \mathrm{kPa}$ for the remainder of the experiment, and extracellular $\mathrm{Ca}^{2+}$ was exchanged for $\mathrm{Ba}^{2+}$ (5-10 mM), containing (in $\mathrm{mM}$ ): $115.5 / 110.5 \mathrm{NaCl}$, $2.5 \mathrm{KCl}, 25 \mathrm{NaHCO}_{3}$, 10 glucose, $1.3 \mathrm{MgCl}_{2}, 5 / 10 \mathrm{BaCl}_{2}$, and $1.2 \mathrm{NaH}_{2} \mathrm{PO}_{4}$, pH 7.4 (95\% $\mathrm{O}_{2}$ and $\left.5 \% \mathrm{CO}_{2}\right)$. VGCC currents were isolated pharmacologically by bath application of tetradotoxin $(1 \mu \mathrm{M})$ and 4-aminopyridine (5 $\mathrm{mM})$ to block voltage-gated sodium and voltage-gated potassium channels, respectively, which were only applied once the nucleated patch was isolated from the remnant (anucleated) neuron and situated in the external ACSF (input resistance range typically 1-5G 2 ). Recording pipettes were fabricated from borosilicate glass that was pulled and fire-polished to a tip resistance between 3 and $6 \mathrm{M} \Omega$ (GC150F, $1.5 \mathrm{~mm}$, Harvard Apparatus, UK) when filled with caesium-based internal solution, containing (in $\mathrm{mM}$ ): $120 \mathrm{CsMeSO}_{4}, 10 \mathrm{TEACl}, 10$ HEPES, $4 \mathrm{Mg}_{2} \mathrm{ATP}$, $0.3 \mathrm{Na}_{3} \mathrm{GTP}, 20$ phosphocreatine, and 0.3 EGTA (pH 7.3 with $\mathrm{CsOH}$; osmolarity $\sim 295-300 \mathrm{mOsm} / \mathrm{kg}$ ). VGCC currents were evoked with a 50-ms depolarising pulse from -80 to $0 \mathrm{mV}$ every $20 \mathrm{~s}(0.05 \mathrm{~Hz})$. Current-voltage $(I-V)$ relationships were investigated by $50-\mathrm{ms}$ step depolarisations from -90 to $+40 \mathrm{mV}$ in $10-\mathrm{mV}$ increments from a holding potential of $-80 \mathrm{mV}$. Linear leak and capacitive currents were subtracted online by a $\mathrm{P} / \mathrm{N}$ protocol ( 15 repetitions of voltage step -80 to $-100 \mathrm{mV}$ ). $1,25(\mathrm{OH})_{2} \mathrm{D}$ was applied at the physiological concentration of $0.1 \mathrm{nM}^{30}$ from a $1-\mathrm{mM}$ stock solution (DMSO). Recordings were made using a MultiClamp 700B 


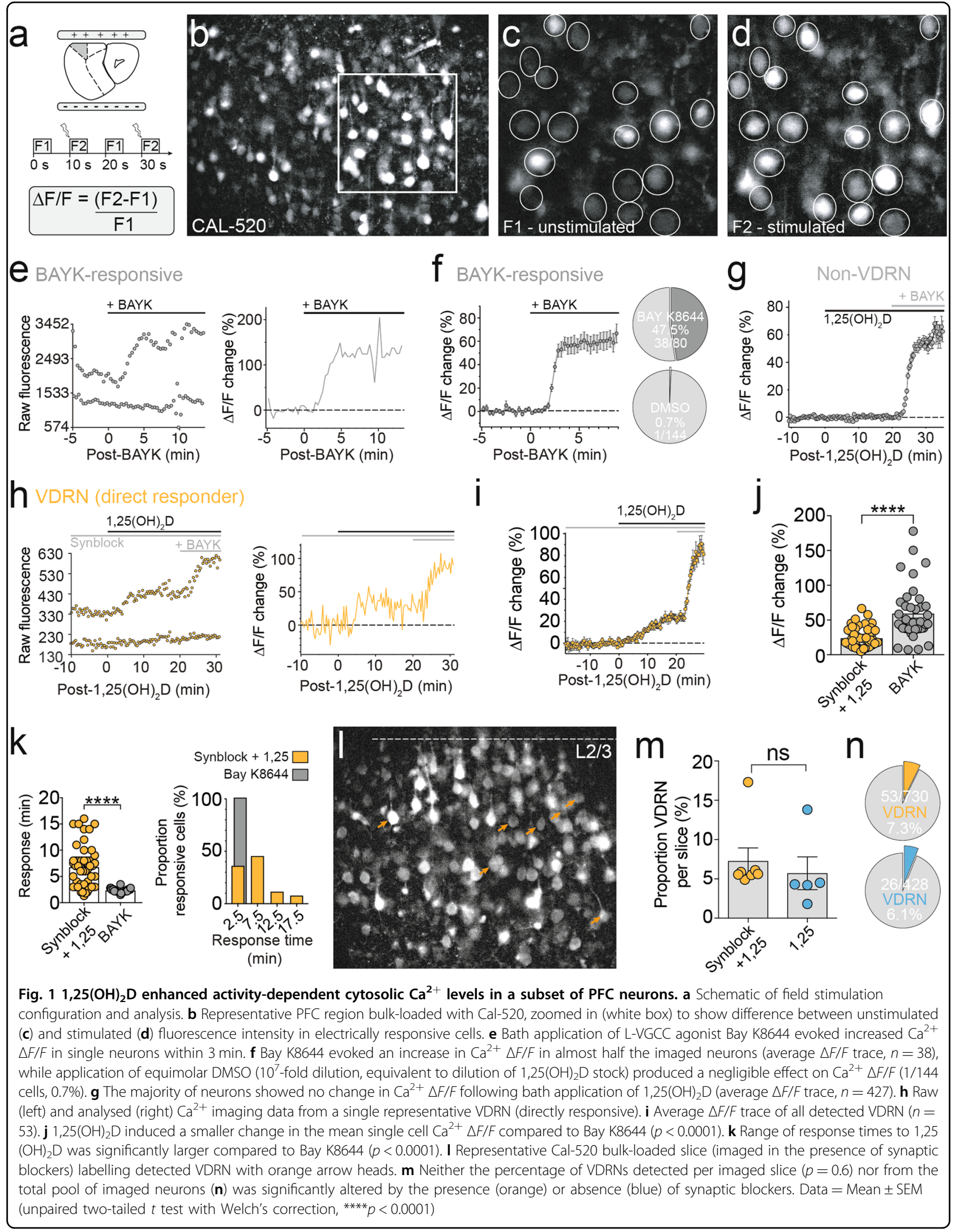


amplifier (Molecular Devices) with Sutter manipulators (MP-285). Recordings were filtered at $6 \mathrm{kHz}$ and digitised at $10-50 \mathrm{kHz}$ using an ITC-18 board (InstruTech, Port Washington, NY), attached to an iMac. Recordings were acquired and analysed offline using Axograph software (Axograph X, version 1.4.4).

\section{Statistics}

Calcium imaging statistics were evaluated using unpaired two-tailed $t$ test with Welch's correction (unequal variances $t$ test). All data were analysed using Prism 7 (GraphPad Software) and are reported as mean \pm SEM. Additional details and experimental design are included in Supplementary Methods.

\section{Results}

Simultaneous measurement of single-cell VGCC activity from a population of neurons

Conventional methods for the functional investigation of VGCC activity have low spatial resolution, in that they involve single-cell recording configurations in order to provide sufficient voltage control. To locate and quantify the effects of $1,25(\mathrm{OH})_{2} \mathrm{D}$ on VGCCs in the brain, we developed a high-throughput imaging method that allowed the simultaneous measure of single-cell activitydependent cytosolic $\mathrm{Ca}^{2+}$ from a population of neurons (Fig. 1a-d). This method combines wide-field $\mathrm{Ca}^{2+}$ fluorescence imaging with field stimulation in brain slices, thereby retaining cortical layer organisation (Fig. 1a). Cytosolic $\mathrm{Ca}^{2+}$ levels were visualised using the fluorescence indicator Cal-520 (50-ms exposure; $0.1 \mathrm{~Hz}$; Fig. 1b), with every second exposure time-locked to field stimulation (F2; $0.05 \mathrm{~Hz}$; Fig. 1c, d). This approach evoked stable activity-dependent increases in cytosolic $\mathrm{Ca}^{2+}$ in postnatal PFC neurons (P8-P12) throughout the imaged area, for extended imaging durations $(>1 \mathrm{~h})$. Bath application of dihydropyridine (DHP) L-VGCC agonist BAYK $(2.5 \mu \mathrm{M})$ confirmed sufficient sensitivity to detect changes in L-VGCC activity (Fig. 1e), resolving changes to $\triangle F / F$ as low as $7 \%\left(59 \pm 6 \%, n=38\right.$; Fig. 1f). BAYK increased $\mathrm{Ca}^{2+}$ $\Delta F / F$ within $3 \mathrm{~min}$ of application $(2.3 \pm 0.05 \mathrm{~min})$, which was consistent with the effect of BAYK on single-channel L-VGCC recordings ${ }^{35}$. Further, BAYK evoked an increased $\mathrm{Ca}^{2+} \Delta F / F$ in $47.5 \%$ of the imaged neurons (Fig. 1f), consistent with L-VGCC protein expression in the $\mathrm{PFC}^{9}$. Application of equimolar DMSO $\left(10^{7}\right.$-fold dilution, equivalent to dilution of $1,25(\mathrm{OH})_{2} \mathrm{D}$ stock) evoked negligible effect on $\mathrm{Ca}^{2+} \Delta F / F$ measured from imaged neurons (1/144 DMSO-responsive neuron, 0.7\%; Fig. 1f).

\section{$1,25(\mathrm{OH})_{2} \mathrm{D}$ enhanced activity-dependent cytosolic $\mathrm{Ca}^{2+}$ levels in a subset of neurons}

Using the approach described above, $1,25(\mathrm{OH})_{2} \mathrm{D}$ $(0.1 \mathrm{nM})$ was bath applied to brain slices containing PFC.
In order to identify neurons directly responsive to 1,25 $(\mathrm{OH})_{2} \mathrm{D}$, calcium imaging was conducted in either the presence (colour-coded orange) or absence (colour-coded blue) of synblock (Supplementary Fig. 1d). While the majority of electrically responsive neurons were nonresponsive to $1,25(\mathrm{OH})_{2} \mathrm{D}$ (Non-VDRN, Fig. 1g), a subset of PFC neurons rapidly responded to $1,25(\mathrm{OH})_{2} \mathrm{D}$ application with significantly enhanced activity-dependent $\mathrm{Ca}^{2+}$ levels (Fig. 1h; Supplementary Fig. 2), termed VDRNs. In the presence of synblock (orange), cytosolic $\mathrm{Ca}^{2+} \Delta F / F$ levels increased by as much as $66.5 \%(24 \pm 2 \%$, $n=53$; Fig. 1i, j) as early as $2 \mathrm{~min}$ following bath application, with the majority of VDRNs responding within $10 \min (6.7 \pm 0.5 \mathrm{~min}, n=53$; Fig. $1 \mathrm{k})$. Notably, both the change in $\mathrm{Ca}^{2+} \Delta F / F$ levels $(p<0.0001$; Fig. $1 \mathrm{j})$ and the range of response times $(p<0.0001$; Fig. $1 \mathrm{k})$ were significantly different compared to neurons responding to the direct-binding L-VGCC agonist BAYK. Application of $1,25(\mathrm{OH})_{2} \mathrm{D}$ in the absence of synblock did not change the $1,25(\mathrm{OH})_{2} \mathrm{D}$-induced increase in $\Delta F / F(29 \pm 4 \%, n=26$; $p=0.17)$ nor the onset of response in detected VDRNs (7.6 \pm 1 min, $n=26 ; p=0.43$ ), suggesting $1,25(\mathrm{OH})_{2} \mathrm{D}$ did not enhance $\mathrm{Ca}^{2+} \Delta F / F$ levels through calcium-permeable AMPA or $N$-methyl-D-aspartate receptors. Mapping directly responsive VDRNs onto their respective $\mathrm{Ca}^{2+}$-imaged areas revealed the scattered nature of VDRN soma localisation throughout the cortical layers of the PFC (Fig. 1l, orange arrows). There was also no significant difference $(p=0.6)$ between the proportion of cells that responded with increased $\mathrm{Ca}^{2+} \Delta F / F$ levels in either the presence $(7.3 \pm 2 \%, n=7$ slices, Fig. $1 \mathrm{~m} ; 53 / 730$ cells, $7.3 \%$, Fig. 1n) or absence (slice mean $=5.7 \pm 2 \%, n=$ 5 slices, Fig. 1m; 26/428 cells, $6.1 \%$, Fig. 1n) of synblock, suggesting that VDRNs did not drive enhanced $\mathrm{Ca}^{2+} \Delta F / F$ levels in local postsynaptic non-VDRN. In summary, wide-field calcium imaging revealed that $1,25(\mathrm{OH})_{2} \mathrm{D}$ directly enhanced activity-dependent $\mathrm{Ca}^{2+}$ levels in a subset of neurons scattered throughout the PFC, within minutes of application.

\section{$1,25(\mathrm{OH})_{2} \mathrm{D}$ enhanced $\mathrm{HVA} \mathrm{Ca}^{2+}$ channel currents in a subset of PFC neurons}

Fluorescent $\mathrm{Ca}^{2+}$ indicators cannot differentiate $\mathrm{Ca}^{2+}$ released intracellularly from $\mathrm{Ca}^{2+}$ that enters a cell through channels in the plasma membrane. In order to test whether $1,25(\mathrm{OH})_{2} \mathrm{D}$ evoked changes in voltage-gated $\mathrm{Ca}^{2+}$ influx, we recorded $\mathrm{HVA} \mathrm{Ca}{ }^{2+}$ currents in nucleated patch configuration from layer $2 / 3$ PFC neurons. Consistent with the above $\mathrm{Ca}^{2+}$ imaging findings, a subset of recorded neurons showed rapidly ( $3 \pm 1$ min onset, $n=5$; Fig. 2a) increased voltage-gated $\mathrm{Ca}^{2+}$ currents $(33 \pm 5 \%$, $n=5$; Fig. $2 \mathrm{a}-\mathrm{d})$ in response to $1,25(\mathrm{OH})_{2} \mathrm{D}(0.1 \mathrm{nM}$; peak response by $8 \pm 2 \mathrm{~min}, n=5)$. Following $1,25(\mathrm{OH})_{2} \mathrm{D}$ application, currents were entirely blocked by the broad- 


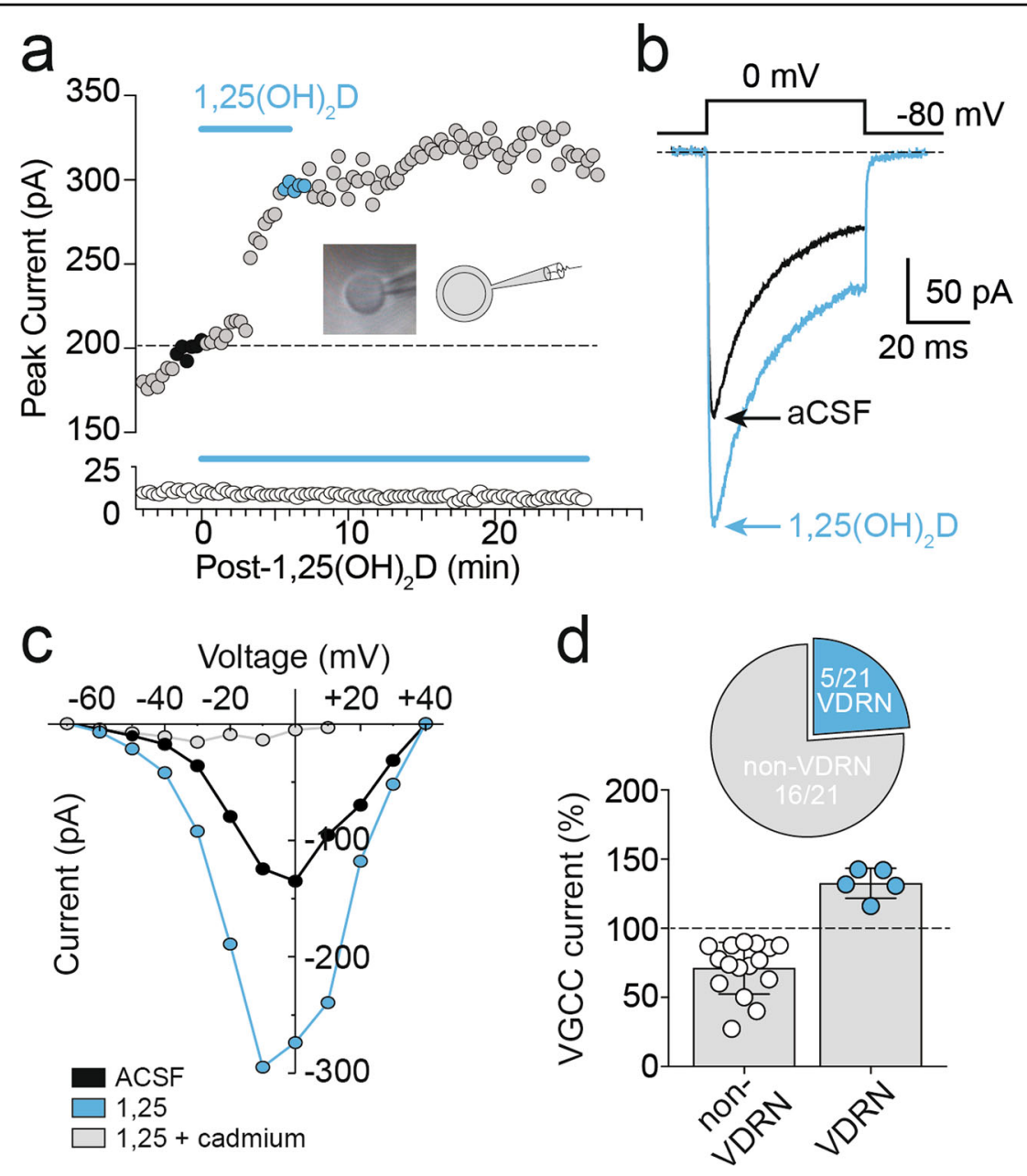

Fig. 2 1,25(OH) $)_{2} \mathrm{D}$ enhanced high-voltage-activated (HVA) $\mathrm{Ca}^{2+}$ channel currents in a subset of PFC neurons. a Baseline VGCC current amplitudes recorded in nucleated patch configuration (averaged in $\mathbf{b}$, black trace) rapidly increased (averaged in $\mathbf{b}$, blue trace) during bath

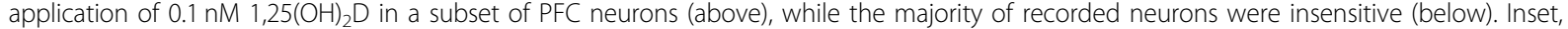
representative and schematic examples of nucleated patch configuration following extraction from whole-cell configuration. c VGCC I-V recorded pre- (black) and post-1,25(OH) $2 \mathrm{D}$ application (blue), abolished by cadmium $(1 \mu \mathrm{M}$, grey). d 1,25(OH) 2 D evoked a mean increase in the recorded HVA $\mathrm{Ca}^{2+}$ current amplitudes of $33 \pm 5 \%$ (blue circles, $n=5$ ), while the majority of cells (open circles) demonstrated peak current amplitude rundown typical of L-VGCC channels $(-29 \pm 5 \% ; n=16)$. Data $=$ Mean \pm SEM

spectrum $\mathrm{Ca}^{2+}$ channel blocker cadmium $(1 \mu \mathrm{M}$; Fig. 2c) to confirm that only HVA $\mathrm{Ca}^{2+}$ currents were evoked. Typical of L-VGCC currents, and despite the inclusion of high phosphocreatine in the recording pipette, the majority of nucleated patch recordings showed rundown in HVA $\mathrm{Ca}^{2+}$ current amplitudes ${ }^{36,37}$ (Fig. 2a, d, white circles).

\section{Enhanced activity-dependent $\mathrm{Ca}^{2+}$ levels mediated by L- type VGCCs}

Since $1,25(\mathrm{OH})_{2} \mathrm{D}$ enhanced $\mathrm{HVA} \mathrm{Ca}{ }^{2+}$ influx in a subset of PFC neurons (Fig. 2), and $1,25(\mathrm{OH})_{2} \mathrm{D}$ is known to modulate L-type VGCC activity in peripheral tissues, we considered whether $1,25(\mathrm{OH})_{2} \mathrm{D}$ enhanced activitydependent $\mathrm{Ca}^{2+}$ levels by rapidly modulating L-VGCC activity. We first assessed whether VDRN expressed functional L-VGCCs by bath applying L-VGCC-specific agonist BAYK $\left(2.5 \mu \mathrm{M}^{38}\right)$ following $1,25(\mathrm{OH})_{2} \mathrm{D}$ application. While BAYK evoked a rapid $\mathrm{Ca}^{2+} \Delta F / F$ increase in approximately half the total imaged neurons (Fig. 1h), the vast majority of VDRNs (48/53, 91\%; Fig. 3a) showed a significant increase in $\mathrm{Ca}^{2+} \Delta F / F$ following BAYK application. Conversely, approximately $12 \%$ of BAYKresponsive neurons were VDRNs (53/438 neurons; $12.7 \pm 3 \%, n=7$ slices). In the presence of $1,25(\mathrm{OH})_{2} \mathrm{D}$, BAYK evoked a similar increase in $\mathrm{Ca}^{2+} \Delta F / F(72 \pm 6 \%$, $n=48, p=0.15$; Fig. $3 \mathrm{~b})$ compared to application of BAYK alone (59 $\pm 6 \%, n=38$; Fig. 1 f), suggesting no facilitative or depressive interaction between the two molecules. 

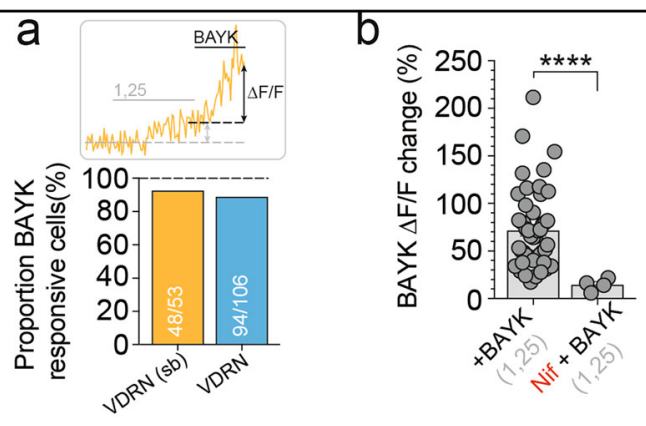

C

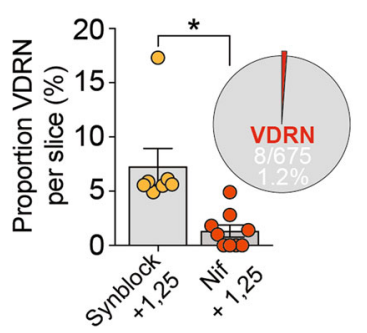

d

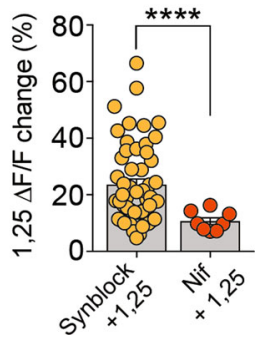

Fig. 3 Enhanced activity-dependent $\mathrm{Ca}^{2+}$ levels mediated by L-type VGCCs. a The majority of VDRNs showed an increased $\mathrm{Ca}^{2+}$ $\triangle F / F$ in response to L-VGCC agonist Bay K8644, suggesting functional L-VGCC expression. $\mathbf{b}$ In the presence of $1,25(\mathrm{OH})_{2} \mathrm{D}$, Bay K8644 increased VDRN $\mathrm{Ca}^{2+} \triangle F / F$ in a manner comparable to Bay K8644 alone (Fig. 1i) and was attenuated by preincubation in L-VGCC antagonist nifedipine $(p<0.0001)$. Pre-incubation of imaged slices in nifedipine significantly reduced both the proportion of detected VDRN ( $c p=0.01$ ) and magnitude of detected $\mathrm{Ca}^{2+} \Delta F / F$ changes in response to $1,25(\mathrm{OH})_{2} \mathrm{D}(\mathbf{d} p<0.0001)$. Data $=$ Mean \pm SEM (Unpaired two-tailed $t$ test with Welch's correction, ${ }^{*} p<0.05$, ${ }^{* * *} p<0.0001$ )

We next tested whether $1,25(\mathrm{OH})_{2} \mathrm{D}$ enhanced activitydependent $\mathrm{Ca}^{2+}$ levels in VDRN through modulation of L-VGCC activity. Slices were preincubated with L-VGCCspecific blocker nif $(10 \mu \mathrm{M} ;>30 \mathrm{~min})$, and baseline calcium imaging was conducted in the presence of nif for a further $20 \mathrm{~min}$ (electrically stimulated 60 times at $0.05 \mathrm{~Hz}$; Supplementary Fig. 1d) to maximise the state and depolarisation dependency of DHP antagonism efficacy ${ }^{31,32}$. Significantly, preincubation in nif almost entirely abolished $1,25(\mathrm{OH})_{2} \mathrm{D}$-induced changes to $\mathrm{Ca}^{2+} \Delta F / F$, attenuating both the proportion of $1,25(\mathrm{OH})_{2} \mathrm{D}$ responsive neurons $(8 / 675,1.2 \%, n=9$ slices; $p=0.01$; Fig. 3c) and the magnitude of detected $\mathrm{Ca}^{2+} \Delta F / F$ changes $(10.7 \pm 1 \%, n=8$ cells, $n=9$ slices; $p<0.0001$; Fig. $3 \mathrm{~d})$. Interestingly, preincubation in nif attenuated BAYKinduced increases in VDRN $\mathrm{Ca}^{2+} \Delta F / F$ to a similar extent $(14 \pm 3 \%, n=4$ cells, $n=9$ slices; $p<0.0001$; Fig. 3b), suggesting that residual $1,25(\mathrm{OH})_{2} \mathrm{D}$-induced changes to $\mathrm{Ca}^{2+} \Delta F / F$ (Fig. 3d) resulted from the incomplete antagonism of nif ${ }^{32,38,39}$. These findings suggest that $1,25(\mathrm{OH})_{2} \mathrm{D}$ enhanced activity-dependent $\mathrm{Ca}^{2+}$ levels in a distinct subset of developing PFC neurons through rapid modulation of L-VGCC activity. Further, this effect was not associated with changes to Cacna1c mRNA levels (Supplementary Fig. 3), suggesting a nongenomic mechanism.

\section{Discussion}

Vitamin D deficiency, a prevalent exposure in many parts of the world ${ }^{40}$, reduces the expected (basal) concentration of $1,25(\mathrm{OH})_{2} \mathrm{D}^{41}$. While developmental vitamin $\mathrm{D}$ deficiency is associated with a range of altered brain outcomes ${ }^{19}$, the assumption to date has been that these properties were mediated via classical genomic pathways (i.e., involving the nuclear receptor VDR). Here we provide evidence that $1,25(\mathrm{OH})_{2} \mathrm{D}$ also affects brain function via rapid, non-genomic mechanisms. Physiological levels of $1,25(\mathrm{OH})_{2} \mathrm{D}$ rapidly enhanced $\mathrm{Ca}^{2+}$ influx through L-VGCCs in a small subset of neurons in the PFC, leading to elevated intracellular calcium levels during neural activity (Fig. 4). We propose that suboptimal concentrations of this secosteroid during critical periods of brain development may result in altered L-VGCC function in VDRNs. Since L-VGCC activity is critical to healthy neurodevelopment ${ }^{7}$, vitamin D deficiency may disrupt the excitability and maturation of VDRNs, with possible consequences for local circuit integration, function, and information processing. This non-genomic mechanism may represent a link between two independent genetic and epidemiologic risk factors for schizophrenia.

\section{$1,25(\mathrm{OH})_{2} \mathrm{D}$ non-genomically modulated L-VGCC activity in a subset of PFC neurons}

We show with single-cell resolution that $1,25(\mathrm{OH})_{2} \mathrm{D}$ rapidly enhanced activity-dependent $\mathrm{Ca}^{2+} \Delta F / F$ through L-VGCCs in a subset of developing PFC neurons. Changes to L-VGCC-mediated $\mathrm{Ca}^{2+}$ influx can be evoked through (1) modulation of single-channel conductance or gating, such as through DHP agonists and antagonists ${ }^{38,42}$ and/or (2) regulation of the number of channels present in the plasma membrane via protein trafficking. Interestingly, the kinetics of this effect were different to those evoked by L-VGCC agonist BAYK, where $1,25(\mathrm{OH})_{2} \mathrm{D}$ induced a smaller mean change to $\mathrm{Ca}^{2+} \triangle F / F$, with a slower mean response time, and was not observed in all neurons that expressed L-VGCCs. This difference likely reflects an alternative mechanism of action compared to BAYK, which binds directly to the pore-forming $\alpha 1$ subunit of L-VGCCs to enhance channel gating. Further, this finding indicates that only a subset of L-VGCCexpressing neurons contained the machinery required for initiation of $1,25(\mathrm{OH})_{2} \mathrm{D}$-evoked effects, which may suggest the involvement of specific auxiliary L-VGCC subunits $^{43,44}$ or second messenger signalling pathways. Indeed, a previous study showed that non-genomic effects of $1,25(\mathrm{OH})_{2} \mathrm{D}$ in neurons are dependent on $\mathrm{Ca}^{2+} / \mathrm{cal}$ modulin-dependent protein kinase II (CaMKII) and 


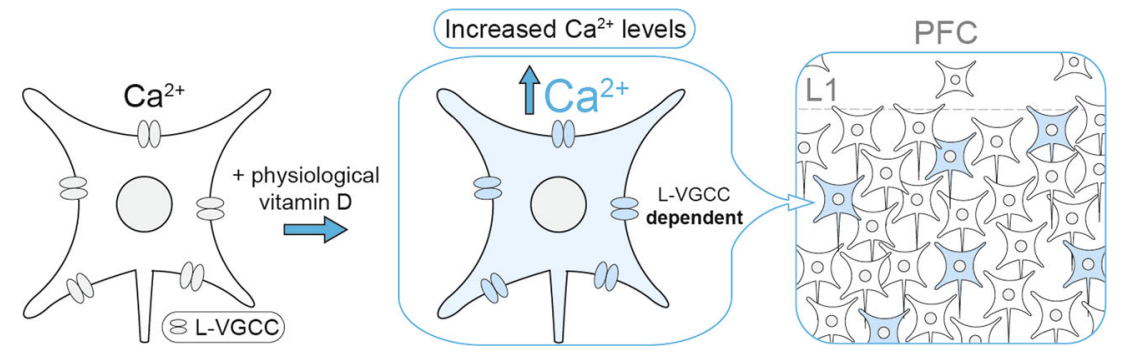

Fig. 4 A non-genomic role for $\mathbf{1 , 2 5 ( O H})_{2} \mathrm{D}$ in the developing brain. VDRNs responded rapidly to $1,25(\mathrm{OH})_{2} \mathrm{D}$ treatment with increased $\mathrm{Ca}^{2+}$ influx mediated by L-VGCCs. Through their modulation of L-VGCC, optimal levels of $1,25(\mathrm{OH})_{2} \mathrm{D}$ may contribute to the healthy development of VDRNs within the maturing cortical circuit, such as through neurite extension, neuronal excitability, and gene expression

phosphoinositide 3-kinase (PI3K) ${ }^{29}$, where both CaMKII and $\mathrm{P} 13 \mathrm{~K}$ have previously been shown to promote trafficking of L-VGCC neurons through the $\beta_{2}$ subunit ${ }^{45,46}$. The propensity of these second messengers to facilitate L-VGCC activity through the $\beta_{2}$ subunit is noteworthy here, since variants of the $\beta_{2}$ gene (CACNB2) have also been associated with an increased risk for schizophrenia $^{2,3}$. In order to determine whether $1,25(\mathrm{OH})_{2} \mathrm{D}$ enhances L-type VGCC $\mathrm{Ca}^{2+}$ influx in VDRNs by increasing $\mathrm{Ca}_{\mathrm{V}} 1.2$ surface expression levels, future studies will require live imaging of $\mathrm{Ca}_{\mathrm{v}} 1.2$ channel trafficking with single-cell resolution. Future studies should also determine: (1) the identity and role of VDRNs in the PFC, (2) whether altered L-VGCC activity during developmental vitamin D deficiency affects VDRN properties and circuit function, and (3) the distribution of VDRNs outside the PFC and at other stages of development.

\section{L-VGCCs, brain development and schizophrenia}

L-VGCCs are highly expressed in the developing brain and are widely known to play a critical role in neuronal development ${ }^{7}$, neuronal excitability, synaptic plasticity, homoeostatic plasticity and the transduction of neuronal activity into gene expression ${ }^{47}$. L-VGCC activity plays a critical role in mediating cortical neurite extension and radial migration ${ }^{8}$, and both ionic and conformational signalling in L-VGCC are required to drive neuronal gene expression $^{48}$. Indeed, disruption to L-VGCC function in hippocampal parvalbumin interneurons during development significantly reduced cell number and dendritic arbor complexity ${ }^{7}$. L-VGCCs are also critical in the regulation of basal and burst firing activity in dopaminergic neurons of the ventral tegmental area ${ }^{49}$, which are considered responsible for the control of basal dopamine levels in downstream areas ${ }^{50}$, and are also the target of significant PFC projections ${ }^{51}$. Notably, both parvalbumin interneurons and the dopamine system are implicated in current hypotheses in schizophrenia research ${ }^{52}$. Critically, disruption to L-VGCC activity has also been implicated in behavioural phenotypes of interest to psychiatry. A recent transgenic animal study suggested that deletion of $\mathrm{Cac}$ nalc in forebrain glutamatergic neurons during embryonic development, but not adulthood, was associated with hyperactivity, impaired hippocampal synaptic plasticity, cognitive impairment and reduced sociability ${ }^{9}$. These findings support the hypothesis that factors influencing L-VGCC activity in the developing brain may contribute to risk of schizophrenia.

In addition to schizophrenia ${ }^{3}$, variants in L-VGCCrelated genes such as $C A C N A 1 C$ and $C A C N B 2$ have also been linked to a range of other mental disorders ${ }^{53}$. In particular, variants in L-VGCC-related genes have been linked to the risk of autism-related phenotypes ${ }^{54}$. Recent studies based on the Generation R birth cohort have found that gestational vitamin D deficiency is also associated with an increased risk of both autism-related traits and autism-spectrum disorder ${ }^{55,56}$. These findings are in keeping with the expectation that genetic and environmental risk factors are often shared across a range of psychiatric phenotypes.

Genetic and epidemiological studies have provided important insights into the aetiology of schizophrenia; however, it is rare that discoveries from these fields converge on a shared neurobiological pathway. Indeed, studies that can combine genetics, epidemiology and basic neuroscience are considered better able to triangulate on causal mechanisms ${ }^{57}$. This approach led us to investigate the links between two established risk factors for schizophrenia: risk variants in L-VGCC genes and developmental vitamin $D$ deficiency. Using functional approaches, we have demonstrated that vitamin D rapidly enhanced L-VGCC activity in a subset of PFC neurons during brain development. We propose that optimal concentrations of $1,25(\mathrm{OH})_{2} \mathrm{D}$ contribute to the normal (expected) development and maturation of VDRNs through the non-genomic modulation of L-VGCC activity. Conversely, we propose that suboptimal concentrations of $1,25(\mathrm{OH})_{2} \mathrm{D}$ may disrupt developmentally critical L-VGCC-dependent processes within the immature cortical circuit. In other words, vitamin D deficiency may 
produce a transient channelopathy-like state, in that the activity of L-VGCCs is altered during critical periods of neurodevelopment. However, unlike genetic diseases that affect L-VGCC activity, vitamin D deficiency is preventable with supplementation. Unravelling the underlying mechanism, as well as the identity and role these neurons play within the circuit, may provide further insight into the aetiology and pathophysiology of schizophrenia.

\section{Acknowledgements}

This project was supported by NHMRC Project grants (APP 1007677, APP 1099709), a John Cade Fellowship (APP1056929) and a Rebecca L Cooper Medical Research Foundation grant (APP 10843). J.J.M. was supported by a Niels Bohr Professorship from the Danish National Research Foundation. V.A. was supported by grants from the Australian Research Council (DP170102402), John T. Reid Charitable Trusts and the Clem Jones Centre for Ageing Dementia Research. S.E.J. is a University of Queensland International Scholar. These funding agencies were not involved in any aspect of the study. We thank Gavin Bird and Karin Bird for general support related to this field of research, Luke Hammond and Christian Loebbe for assistance with microscopy and $\mathrm{Ca}^{2+}$ imaging, Suzy Alexander and staff of the QBI Animal House for assistance with the animal studies and Jack Dou and Hilary Yong for assistance with neuronal culture studies.

\section{Author details}

'Queensland Brain Institute, University of Queensland, St. Lucia, QLD 4072, Australia. ${ }^{2} \mathrm{Clem}$ Jones Centre for Ageing Dementia Research, University of Queensland, St. Lucia, QLD 4072, Australia. Institute for Molecular Bioscience, The University of Queensland, St Lucia, QLD 4072, Australia. ${ }^{4}$ Queensland Centre for Mental Health Research, The Park Centre for Mental Health, Wacol, QLD 4076, Australia. ${ }^{5}$ Department of Biomedicine, Aarhus University, 8000 Aarhus, Denmark. ${ }^{6}$ iPSYCH, The Lundbeck Foundation Initiative for Integrative Psychiatric Research, 8000 Aarhus, Denmark. ${ }^{7}$ Center for Neonatal Screening, Department for Congenital Disorders, Statens Serum Institut, 2300 Copenhagen, Denmark. ${ }^{8}$ National Centre for Register-Based Research, Aarhus University, 8000 Aarhus, Denmark. ${ }^{9}$ Centre for Integrated Register-based Research, Aarhus University, 8000 Aarhus, Denmark. ${ }^{10}$ Brain Research Centre and Department of Biology, Southern University of Science and Technology, Nanshan District, Shenzhen, Guangdong Province, P. R. China.

\section{Authors' contributions}

All authors designed research; H.G., V.A., X.C., M.C.T. and S.E.J. performed research; H.G., V.A. and X.C. analysed data; H.G., X.C., V.A. and J.J.M. wrote the paper.

\section{Conflict of interest}

The authors declare that they have no conflict of interest.

\section{Publisher's note}

Springer Nature remains neutral with regard to jurisdictional claims in published maps and institutional affiliations.

Supplementary Information accompanies this paper at (https://doi.org/ 10.1038/s41398-019-0626-z).

Received: 3 November 2018 Revised: 10 October 2019 Accepted: 20 October 2019

Published online: 11 November 2019

\section{References}

1. McGrath, J., Saha, S., Chant, D. \& Welham, J. Schizophrenia: a concise overview of incidence, prevalence, and mortality. Epidemiol. Rev. 30, 67-76 (2008).
2. Schizophrenia Working Group of the Psychiatric Genomics Consortium. Biological insights from 108 schizophrenia-associated genetic loci. Nature 511, 421-427 (2014).

3. Purcell, S. M. et al. A polygenic burden of rare disruptive mutations in schizophrenia. Nature 506, 185-190 (2014).

4. Glessner, J. T. et al. Strong synaptic transmission impact by copy number variations in schizophrenia. Proc. Natl Acad. Sci. USA 107, 10584-10589 (2010).

5. Yoshimizu, T. et al. Functional implications of a psychiatric risk variant within CACNA1C in induced human neurons. Mol. Psychiatry 20, 162-169 (2015).

6. Redmond, L., Kashani, A. H. \& Ghosh, A. Calcium regulation of dendritic growth via CaM kinase IV and CREB-mediated transcription. Neuron 34 999-1010 (2002).

7. Jiang, M. \& Swann, J. W. A role for L-type calcium channels in the maturation of parvalbumin-containing hippocampal interneurons. Neuroscience 135, 839-850 (2005)

8. Kamijo, S. et al. A critical neurodevelopmental role for L-type voltage-gated calcium channels in neurite extension and radial migration. J. Neurosci. 38, 5551-5566 (2018).

9. Dedic, N. et al. Cross-disorder risk gene CACNA1C differentially modulates susceptibility to psychiatric disorders during development and adulthood. Mol. Psychiatry 23, 533-543 (2018).

10. Holick, M. F. Vitamin D deficiency. N. Engl. J. Med. 357, 266-281 (2007).

11. Cantor-Graae, E. \& Selten, J. P. Schizophrenia and migration: a meta-analysis and review. Am. J. Psychiatry 162, 12-24 (2005).

12. Davies, G., Welham, J., Chant, D., Torrey, E. F. \& McGrath, J. A systematic review and meta-analysis of Northern Hemisphere season of birth studies in schizophrenia. Schizophr. Bull. 29, 587-593 (2003).

13. McGrath, J. J. et al. Neonatal vitamin D status and risk of schizophrenia: a population-based case-control study. Arch. Gen. Psychiatry 67, 889-894 (2010).

14. Eyles, D. W. et al. The association between neonatal vitamin D status and risk of schizophrenia. Sci. Rep. 8, 17692 (2018).

15. Eyles, W., Smith, S., Kinobe, R., Hewison, M. \& McGrath, J. The receptor for vitamin $D$ and the enzyme responsible for its synthesis are widely distributed in human brain. Int. J. Neuropsychopharmacol. 7, S264-S264 (2004).

16. Cui, X., Groves, N. J., Burne, T. H. J., Eyles, D. W. \& McGrath, J. J. Low vitamin D concentration exacerbates adult brain dysfunction. Am. J. Clin. Nutr. 97, 907-908 (2013)

17. Kesby, J. P., Burne, T. H., McGrath, J. J. \& Eyles, D. W. Developmental vitamin D deficiency alters MK 801-induced hyperlocomotion in the adult rat: An animal model of schizophrenia. Biol. Psychiatry 60, 591-596 (2006).

18. Luan, W. et al. Developmental vitamin D (DVD) deficiency reduces Nurr1 and TH expression in post-mitotic dopamine neurons in rat mesencephalon. Mol. Neurobiol. 55, 2443-2453 (2017).

19. Cui, X., Pelekanos, M., Burne, T. H., McGrath, J. J. \& Eyles, D. W. Maternal vitamin $D$ deficiency alters the expression of genes involved in dopamine specification in the developing rat mesencephalon. Neurosci. Lett. 486, 220-223 (2010).

20. Kesby, J. P. et al. Developmental vitamin D deficiency alters multiple neurotransmitter systems in the neonatal rat brain. Int. J. Dev. Neurosci. 62, 1-7 (2017).

21. Eyles, D. W. et al. Developmental vitamin D deficiency causes abnormal brain development. Psychoneuroendocrinology 34(Suppl 1), S247-S257 (2009).

22. Eyles, D., Brown, J., Mackay-Sim, A., McGrath, J. \& Feron, F. Vitamin D3 and brain development. Neuroscience 118, 641-653 (2003).

23. Brewer, L. D., Porter, N. M., Kerr, D. S., Landfield, P. W. \& Thibault, O. Chronic 1alpha,25-(OH)2 vitamin D3 treatment reduces Ca2+ -mediated hippocampal biomarkers of aging. Cell Calcium 40, 277-286 (2006).

24. Brewer, L. D. et al. Vitamin D hormone confers neuroprotection in parallel with downregulation of L-type calcium channel expression in hippocampal neurons. J. Neurosci. 21, 98-108 (2001).

25. Li, B., Chik, C. L., Taniguchi, N., Ho, A. K. \& Karpinski, E. 24,25(OH)2 vitamin D3 modulates the L-type Ca2+ channel current in UMR 106 cells: involvement of protein kinase A and protein kinase C. Cell calcium 19, 193-200 (1996).

26. Morelli, S., de Boland, A. R. \& Boland, R. L. Generation of inositol phosphates, diacylglycerol and calcium fluxes in myoblasts treated with 1,25-dihydroxyvitamin D3. Biochem. J. 289(Pt 3), 675-679 (1993).

27. Kajikawa, M. et al. An insulinotropic effect of vitamin $D$ analog with increasing intracellular $\mathrm{Ca} 2+$ concentration in pancreatic beta-cells through nongenomic signal transduction. Endocrinology 140, 4706-4712 (1999).

28. Hii, C. S. \& Ferrante, A. The non-genomic actions of vitamin D. Nutrients 8 , 135 (2016). 
29. Zanatta, L. et al. 1alpha,25-dihydroxyvitamin $\mathrm{D}(3)$ mechanism of action: modulation of L-type calcium channels leading to calcium uptake and intermediate filament phosphorylation in cerebral cortex of young rats. Biochim. Biophys. Acta 1823, 1708-1719 (2012).

30. Zanatta, L. et al. 1alpha,25-Dihydroxyvitamin $\mathrm{D}(3)$ signaling pathways on calcium uptake in 30-day-old rat Sertoli cells. Biochemistry 50, 10284-10292 (2011).

31. Bean, B. P. Nitrendipine block of cardiac calcium channels: high-affinity binding to the inactivated state. Proc. Natl Acad. Sci. USA 81, 6388-6392 (1984).

32. Helton, T. D., Xu, W. \& Lipscombe, D. Neuronal L-type calcium channels open quickly and are inhibited slowly. J. Neurosci. 25, 10247-10251 (2005).

33. Sather, W., Dieudonne, S., MacDonald, J. F. \& Ascher, P. Activation and desensitization of $\mathrm{N}$-methyl-D-aspartate receptors in nucleated outside-out patches from mouse neurones. J. Physiol. 450, 643-672 (1992).

34. Martina, M. \& Jonas, P. Functional differences in $\mathrm{Na}+$ channel gating between fast-spiking interneurones and principal neurones of rat hippocampus. J. Physiol. 505(Pt 3), 593-603 (1997).

35. Nowycky, M. C., Fox, A. P. \& Tsien, R. W. Three types of neuronal calcium channel with different calcium agonist sensitivity. Nature 316, 440-443 (1985).

36. Forscher, P. \& Oxford, G. S. Modulation of calcium channels by norepinephrine in internally dialyzed avian sensory neurons. J. Gen. Physiol. 85, 743-763 (1985).

37. Almog, M. \& Korngreen, A. Characterization of voltage-gated $\mathrm{Ca}(2+)$ conductances in layer 5 neocortical pyramidal neurons from rats. PLOS ONE 4, e4841 (2009)

38. Xu, W. \& Lipscombe, D. Neuronal Ca(M)1.3alpha(1) L-type channels activate at relatively hyperpolarized membrane potentials and are incompletely inhibited by dihydropyridines. J. Neurosci. 21, 5944-5951 (2001).

39. Fox, A. P., Nowycky, M. C. \& Tsien, R. W. Kinetic and pharmacological properties distinguishing three types of calcium currents in chick sensory neurones. J. Physiol. 394, 149-172 (1987).

40. Palacios, C. \& Gonzalez, L. Is vitamin D deficiency a major global public health problem? J. Steroid Biochem. Mol. Biol. 144 (Pt A), 138-145 (2014).

41. Zittermann, A., Ernst, J. B., Birschmann, I. \& Dittrich, M. Effect of vitamin D or activated vitamin $\mathrm{D}$ on circulating 1,25-dihydroxyvitamin $\mathrm{D}$ concentrations: a systematic review and metaanalysis of randomized controlled trials. Clin. Chem. 61, 1484-1494 (2015).
42. Grabner, M., Wang, Z., Hering, S., Striessnig, J. \& Glossmann, H. Transfer of 1,4dihydropyridine sensitivity from L-type to class A (BI) calcium channels. Neuron 16, 207-218 (1996).

43. Pichler, M. et al. Beta subunit heterogeneity in neuronal L-type Ca2+ channels. J. Biol. Chem. 272, 13877-13882 (1997).

44. McEnery, M. W. et al. Differential expression and association of calcium channel subunits in development and disease. J. Bioenerg. Biomembr. 30, 409-418 (1998).

45. Viard, P. et al. PI3K promotes voltage-dependent calcium channel trafficking to the plasma membrane. Nat. Neurosci. 7, 939-946 (2004).

46. Grueter, C. E. et al. L-type Ca2+ channel facilitation mediated by phosphorylation of the beta subunit by CaMKII. Mol. Cell 23, 641-650 (2006).

47. Nanou, E. \& Catterall, W. A. Calcium channels, synaptic plasticity, and neuropsychiatric disease. Neuron 98, 466-481 (2018).

48. Li, B., Tadross, M. R. \& Tsien, R. W. Sequential ionic and conformational signaling by calcium channels drives neuronal gene expression. Science 351, 863-867 (2016).

49. Liu, Y. et al. Cav1.2 and Cav1.3 L-type calcium channels regulate dopaminergic firing activity in the mouse ventral tegmental area. J. Neurophysiol. 112, 1119-1130 (2014).

50. Philippart, F. et al. Differential somatic $\mathrm{Ca} 2+$ channel profile in midbrain dopaminergic neurons. J. Neurosci. 36, 7234-7245 (2016).

51. Murugan, M. et al. Combined social and spatial coding in a descending projection from the prefrontal cortex. Cell 171, 1663.e16-1677.e16 (2017).

52. Chung, D. W., Fish, K. N. \& Lewis, D. A. Pathological basis for deficient excitatory drive to cortical parvalbumin interneurons in schizophrenia. Am. J. Psychiatry 173, 1131-1139 (2016).

53. Cross-disorder Group of the Psychiatric Genomics Consortium. Identification of risk loci with shared effects on five major psychiatric disorders: a genomewide analysis. Lancet 381, 1371-1379 (2013).

54. Li, J. et al. Schizophrenia related variants in CACNA1C also confer risk of autism PLOS ONE 10, e0133247 (2015).

55. Vinkhuyzen, A. A. E. et al. Gestational vitamin D deficiency and autism-related traits: the Generation R Study. Mol. Psychiatry 23, 240-246 (2018).

56. Vinkhuyzen, A. A. E. et al. Gestational vitamin D deficiency and autism spectrum disorder. Br. J. Psychiatry Open 3, 85-90 (2017).

57. Munafo, M. R. \& Davey Smith, G. Robust research needs many lines of evidence. Nature 553, 399-401 (2018). 